\title{
A CASE OF HETEROTOPIC PREGNANCY WITH RUPTURED ECTOPIC PREGNANCY
}

Bhupesh H. Gaikwad ${ }^{1}$

\section{HOW TO CITE THIS ARTICLE:}

Bhupesh H. Gaikwad. "A Case of Heterotopic Pregnancy with Ruptured Ectopic Pregnancy". Journal of Evolution of Medical and Dental Sciences 2015; Vol. 4, Issue 64, August 10; Page: 11269-11270,

DOI: $10.14260 /$ jemds/2015/1625

ABSTRACT: HETROTOPIC pregnancy is rare and life threatening condition which can be easily missed. We are hereby present an interesting instance of heterotopic pregnancy after in-vitro fertilization.(1)

KEYWORDS: Heterotopic pregnancy can acutely present with devastating complication.

INTRODUCTION: CASE PRESENTATION: A 25yr old female $\mathrm{G}_{2} \mathrm{P}_{1} \mathrm{D}_{1}$, with one and half month's amenorrhoea was referred from private hospital, with D/D of OHSS or ruptured ectopic pregnancy.

Patient complained of giddiness breathlessness associated with PV spotting and abdominal pain since the same morning. She gave no history of vomiting syncopal attack or fever.

Patient had undergone treatment of infertility with superovulation and IVF. The follow up USG at $5 \mathrm{wks}$.

Showed intra-uterine pregnancy and she was prophylactically started on enoxaparin $20 \mathrm{mg}$ S/C once daily.

At admission patients general condition seemed moderate with tachycardia $(130 / \mathrm{min})$ and thread pulse. BP was recorded to be $90 / 40 \mathrm{~mm} \mathrm{Hg}$. Patient was severely pale with grade 3 pallor. She had abdominal distension with full flanks. Abdominal paracentesis revealed non-clotted blood.

Per-vaginal examination showed 5 wks sized uterus with left formicial tenderness. ${ }^{2,3}$

Emergency sonography showed left ruptured ectopic pregnancy with hemoperitoneum with single live 6 wks intrauterine foetus.

She was resuscitated with 2 pints of PCV and was shifted to OT urgently for exploratory laparotomy.

Left isthmic fallopian tube was found to be ruptured for which left salpingectomy was performed. She was monitored in ICU for next 24 hrs during which 2 pints of whole blood were transfused.

USG after 2 days confirmed 6 wks live intrauterine pregnancy. Patient was registered and is being followed up regularly. Now patient came with 35 weeks with IUGR with severe oligohydraminos for which LSCS was done. Baby weight $1.4 \mathrm{~kg}$ and admitted in NICU for low birth weight.

CONCLUSION AND DISCUSSION: heterotopic pregnancy can acutely present with devastating complications which may require prompt diagnosis and specialist treatment.4,5,6,7 IVF treatment patients should be closely followed up so that early detection and management can improve the outcome in such precious intrauterine pregnancies. ${ }^{8}$ 


\section{REFERENCES:}

1. Govindarajan MJ, rajan R: heterotopic pregnancy in natural conception. J hum rerod sci 1 (1): 37-38.

2. Hirose M. nomura T, wakuda K, Ishguru T, Yoshida Y: combained intrauterine and ovary pregnancy: a case report, asia oceana J obstet gynaecol 1994, 20: 20-05.

3. Peleg D, bar-hava, neaman-leaven M, Ashkena, Ben-Rafaelz J: early diagnosis and successful non surgical treatment of viable combined intrauterine and cervical pregnancy. Fertile steril 1994, 62: 405.

4. Alsunaidi M: an unexpected spontaneous triplet heterotopic pregnancy, Saudi med J 2005, 26 (1): 136-138.

5. Jeong H, park I, Yoon S, lee N, kim H, park S: heterotopic triplet pregnancy with bilateral tubal and intrauterine pregnancy after spontaneous conception. Eur J obstet gynecol 2009, 142: 161162.

6. Raziel A, friedler S, herman A, Strassburger D, maymon R, ron-el R: recurrent heterotopic pregnancy after repeated in-vitro fertilization treatment. Hum rep 1997, 12: 1810-1812.

7. Jerrad D, Tso E, Salik R, Barish RA: unsuspected heterotopic pregnancy in a women without risk factors. Am J emerg Med 1992, 10: 58-60.

8. De Voe RW, Pratt JH: simultaneous intrauterine and extrauterine pregnancy. Am J obstet Gynaecol 1948, 56: 1119-1126.

\section{AUTHORS:}

1. Bhupesh H. Gaikwad

\section{PARTICULARS OF CONTRIBUTORS:}

1. Associate Professor, Department of Obstetrics \& Gynaecology, RCSM Government Medical College, Kolhapur, Maharashtra.

FINANCIAL OR OTHER COMPETING INTERESTS: None

\section{NAME ADDRESS EMAIL ID OF THE CORRESPONDING AUTHOR:}

Dr. Bhupesh H. Gaikwad, Flat No. 08, Girnar Heights, Rajarampuri, $6^{\text {th }}$ Lane, Near State Bank of India, Kolhapur-416008.

E-mail: bhupeshgaikwad@rediffmail.com

Date of Submission: 21/05/2015.

Date of Peer Review: 29/05/2015.

Date of Acceptance: 24/06/2015.

Date of Publishing: 10/08/2015. 